\title{
Behaviour of an iris model and the pupil block hypothesis
}

\author{
H. WYATT AND J. GHOSH \\ St. Paul's Eye Hospital, Liverpool
}

While the immediate cause of primary acute glaucoma is known to be obstruction of the anterior chamber angle by peripheral iris tissue, the mechanism leading to angle closure remains uncertain.

One hypothesis which has been proposed to explain the phenomenon involves the concept of relative pupil block. It is suggested that the iris, stretched across the lens, obstructs the flow of aqueous from the posterior to the anterior chambers. A pressure gradient between the two chambers is necessary for flow to continue, and the resistance to flow is known as relative pupil block. If the pupil block increases a greater pressure is required to force aqueous between the apposing surfaces of the lens and iris, causing the peripheral iris to bow forwards and touch the angle structures. The drainage meshwork is obstructed, the intraocular pressure rises rapidly, and acute congestive glaucoma may follow (Chandler, 1952; Barkan, 1954).

Theoretical analyses of the pupil block mechanism have been attempted, for example, by Lowe (1966) and by Mapstone (1968). However, the physical basis of the theory remains untested. This paper reports preliminary observations on the behaviour of an annular elastic membrane stretched across a ball, and the findings are related to the pupil block hypothesis.

\section{Method}

A model was built using a plastic jar, with an annular elastic membrane stretched across its top to represent the iris (Fig. I, overleaf). The central aperture of the membrane was blocked by a ball to represent the lens. Air blown into the jar from below escaped through the gap between the membrane and the ball causing the membrane to bow forward, and the profile of the membrane was plotted on graph paper. In this way the effect of changes in air flow, in membrane tension, in membrane aperture, and in ball position was studied.

The jar, which was $13 \mathrm{~cm}$. high and I $\mathrm{cm}$. wide, was covered by a lid held on by four springs. A hole of $10 \mathrm{~cm}$. diameter was cut in the lid, and an annular elastic membrane was stretched across the hole and held in place by a plastic ring clamped under four nuts. The membrane was prepared from surgical gloves and the hole in its centre, representing the pupil, was cut to a measured diameter while the membrane was slack. When the membrane was stretched in position the change in diameter of the central hole gave an indication of the tension in the membrane.

A threaded brass rod was fixed to the base of the jar and projected through the centre of the hole in the lid. A ball $6.4 \mathrm{~cm}$. in diameter, with a threaded central bush, was screwed down the rod into the membrane opening, so that its position with relation to the plane of the lid could be varied.

Air was blown from an electrically driven pump through an anaesthetic flow-meter and into the jar. The pressure in the jar was measured using a water-filled U-tube manometer. 


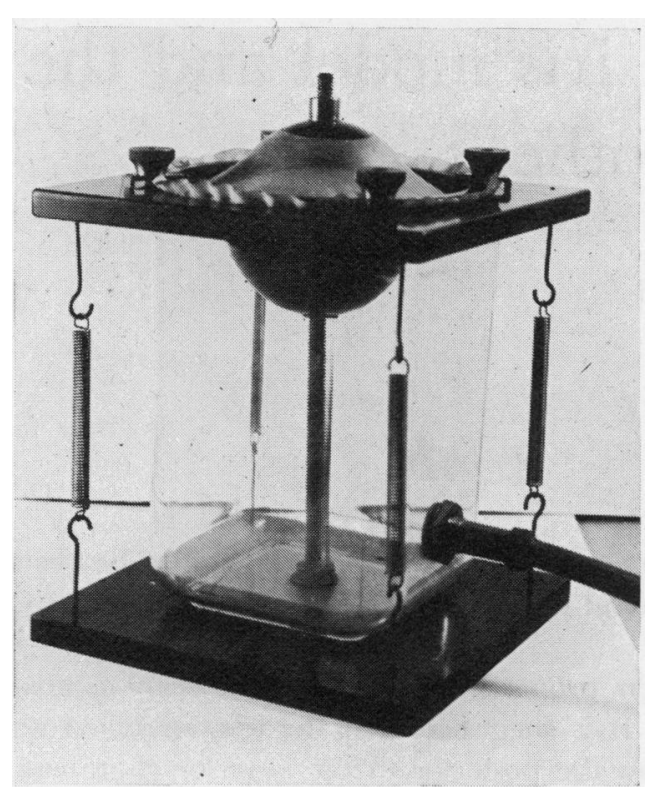

FIG. I The model

Changes in the membrane shape were plotted using a modified jig-gauge.

In each experiment the following observations and measurements were made:

(I) The diameter of the aperture in the membrane.

(2) The position of the ball in relation to the plane of the lid.

(3) The air flow through the model.

(4) The pressure behind the membrane.

(5) The resulting profile of the membrane.

\section{Results}

(A) EFFECT OF GHANGES IN AIR FLOW UPON MEMBRANE SHAPE

In this experiment the membrane was set so that a hole which was $1 \mathrm{~cm}$. initially became $2 \mathrm{~cm}$. in diameter when stretched over the ball. The ball was adjusted to project $2.5 \mathrm{~cm}$. above the plane of the lid.

Membrane shape was recorded at air flows of o, I00, 200, 300, 400, 500, 750, 1,000, and은 $\mathrm{I}, 500 \mathrm{ml} . / \mathrm{min}$. A selection of the results is shown in Fig. 2 (opposite).

At zero flow the membrane adopted a shallow S-shaped curve, forming a hollow between the point of contact with the ball and the periphery (Fig. 2a). As the air flow: increased that part of the membrane which was not in contact with the ball began to move $\mathcal{N}^{\circ}$ forwards, flattening the S-shaped curve, and simultaneously the outer part of the area of contact began to lift off the ball (Figs $2 b, c$, and $d$ ).

Maximum forward bowing was reached at an air flow of $500 \mathrm{ml} . / \mathrm{min}$., when only the edge of the central aperture touched the ball (Fig. $2 d$ ). Further increase of air flow did? not increase the forward bowing of the membrane, which at this stage formed a segment $\frac{0}{0}$ of a sphere.

Forward bowing of the membrane was associated with an increase in pressure behind定 the membrane (Table I). The diameter of the central aperture in the membrane did noto change by a measurable amount between the least and greatest air flows. 
Table I Results from first experiment, using single membrane with ball projecting $2.5 \mathrm{~cm}$. above plane of lid

\begin{tabular}{|c|c|c|c|}
\hline $\begin{array}{l}\text { Air flow } \\
(\mathrm{ml} . / \mathrm{min} .)\end{array}$ & $\begin{array}{l}\text { Pressure } \\
\text { (cm.water) }\end{array}$ & $\begin{array}{l}\text { Resistance } \\
(\mathrm{cm} . / \text { l./min. })\end{array}$ & $\begin{array}{l}\text { Contact area* } \\
\text { between membrane } \\
\text { and ball }(\square \mathrm{cm} . / \pi)\end{array}$ \\
\hline o & o & o & $6 \cdot 38$ \\
\hline 100 & $5 \cdot 7$ & $57^{\circ} \mathrm{O}$ & $5 \cdot 08$ \\
\hline 200 & 1 0.6 & $53 \cdot 0$ & $3 \cdot 46$ \\
\hline 300 & 15.7 & $52 \cdot 3$ & $\mathbf{I} \cdot 59$ \\
\hline 400 & $18 \cdot 0$ & $45^{\circ} \mathrm{O}$ & 0.98 \\
\hline 500 & $18 \cdot 5$ & $37 \cdot 0$ & 0.58 \\
\hline 750 & I 8.8 & $25^{\circ} 0$ & o \\
\hline I, OOO & I 8.9 & I $8 \cdot 9$ & 0 \\
\hline 1,500 & $190^{\circ}$ & $12 \cdot 7$ & o \\
\hline
\end{tabular}

* These figures are an approximation, being calculated for flat and not spherical surfaces

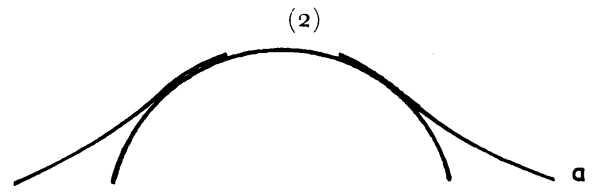

FIG. 2 Profiles of a single-thickness membrane at air flows of (a) o, (b) 200, (c) 300, (d) $500 \mathrm{ml} . / \mathrm{min}$. Ball set to project $2 \cdot 5 \mathrm{~cm}$. above plane of lid
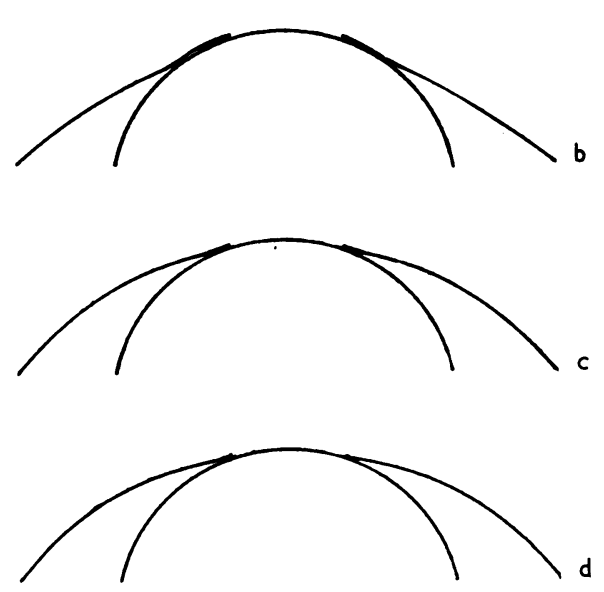

(B) EFFEGT OF CHANGING MEMBRANE TENSION

In the second series of experiments two thicknesses of membrane were cut, each with a central hole of $\mathrm{I} \mathrm{cm}$. diameter, and the doubled membrane was stretched over the ball until the central aperture was $2 \mathrm{~cm}$. in diameter. By doubling the thickness of the membrane and stretching the doubled membrane to the same degree as the single membrane the effect of doubling the membrane tension was achieved. In every other way the conditions of the experiment were identical with those described for the single membrane.

A selection of the results is shown in Fig. 3 (overleaf). The air flows in Figs $3 a, b, c$, and $d$ were the same as those in Figs $2 a, b, c$ and $d$.

No difference could be detected between any of the curves when Figs 2 and 3 were compared, although calculation of contact areas from the measured contact arcs suggested that the contact area of the doubled membrane was greater than that of the single membrane at the same air flow (Tables I and II). Maximum forward bowing occurred at $500 \mathrm{ml} . / \mathrm{min}$. as for the single membrane, and again the central aperture diameter did not change by a measurable amount. The increases of pressure corresponding to increases of flow were greater than for the single membrane (Table II overleaf).

\section{(C) EFFECT OF GHANGING MEMBRANE APERTURE}

Membrane profiles were plotted with different membrane apertures when the ball projected $2.5 \mathrm{~cm}$. above the plane of the lid and the air flow was $1,500 \mathrm{ml} . / \mathrm{min}$.

Apertures were cut in the slack membrane at diameters of I, 2, 3, 4, and $5 \mathrm{~cm}$., and the aperture diameters when the membrane was stretched over the ball are shown in Table III (overleaf).

A selection of the resulting profiles is shown in Fig. $4 a, b, c, d$ (overleaf). A decrease in the membrane aperture led to an increase in forward bowing of the membrane. 
Table II Results from second experiment, using double membrane with ball projecting $2.5 \mathrm{~cm}$. above plane of lid

\begin{tabular}{cccl}
\hline $\begin{array}{l}\text { Air flow } \\
(\text { ml./min. })\end{array}$ & $\begin{array}{l}\text { Pressure } \\
(\mathrm{cm} . \text { water })\end{array}$ & $\begin{array}{l}\text { Resistance } \\
(\mathrm{cm} . / \mathrm{l} . / \text { min. })\end{array}$ & $\begin{array}{l}\text { Contact area* } \\
\text { between membrane } \\
\text { and ball }\left(\square_{\mathrm{cm} .} / \pi\right)\end{array}$ \\
\hline o & 0 & 0 & $6 \cdot 38$ \\
100 & $8 \cdot 3$ & $83 \cdot 5$ & $5 \cdot 32$ \\
200 & $16 \cdot 3$ & $81 \cdot 5$ & $3 \cdot 90$ \\
300 & $24 \cdot 4$ & $81 \cdot 3$ & $2 \cdot 28$ \\
400 & $30 \cdot 6$ & $76 \cdot 5$ & $1 \cdot 28$ \\
500 & $34 \cdot 0$ & $68 \cdot 0$ & $0 \cdot 45$ \\
750 & $36 \cdot 8$ & $49 \cdot 0$ & 0 \\
1,000 & $37 \cdot 7$ & $37 \cdot 7$ & 0 \\
1,500 & $38 \cdot 3$ & $25 \cdot 5$ & 0
\end{tabular}

* These figures are an approximation, being calculated for flat and not spherical surfaces

FIG. 3 Profiles of a double-thickness membrane at air flows of (a) o, (b) 200, (c) 300 , (d) $500 \mathrm{ml} . / \mathrm{min}$. Ball set to project $2 \cdot 5 \mathrm{~cm}$. above plane of lid

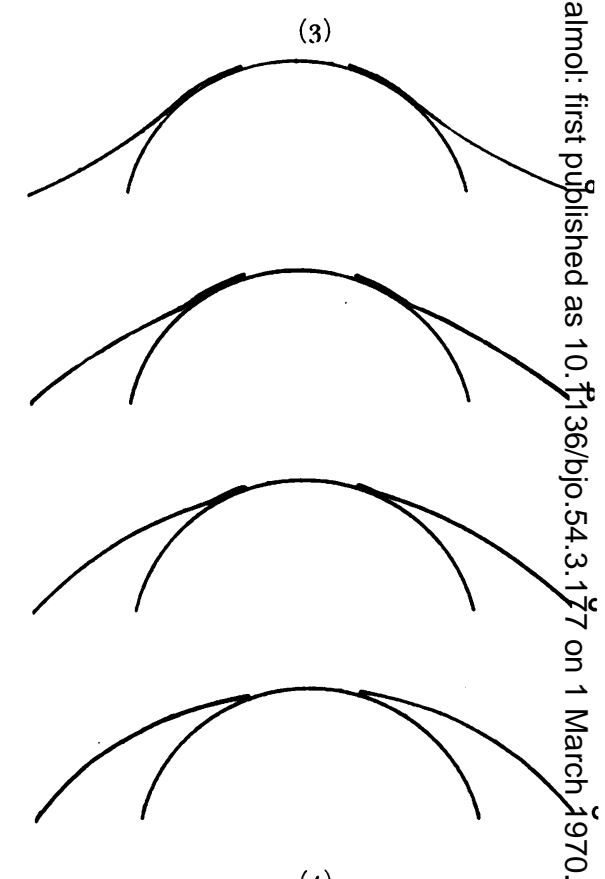

(4)

Table III Diameter of aperture in membrane when stretched over ball, compared with aperture in slack membrane, in Experiment $C$

\begin{tabular}{lllllllll}
\hline $\begin{array}{l}\text { Aperture } \\
\text { (cm. } \\
\text { diameter })\end{array}$ & Slack & & $0 \cdot 9$ & $2 \cdot 0$ & $3 \cdot 0$ & $4 \cdot 0$ & $5 \cdot 0$ & $6 \cdot 0$ \\
\cline { 2 - 7 } & Stretched & $2 \cdot 1$ & $3 \cdot 2$ & $4 \cdot 1$ & $5 \cdot 0$ & $5 \cdot 6$ & $6 \cdot 3$
\end{tabular}
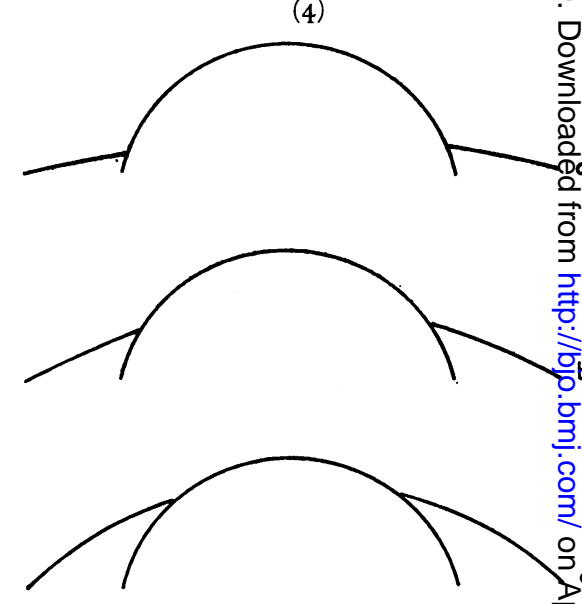

FIG. 4 Profiles of single-thickness membranes with different sized apertures as shown in Table III. Ball set to project $2.5 \mathrm{~cm}$. above plane of lid. Air flow 1,500 ml./min.

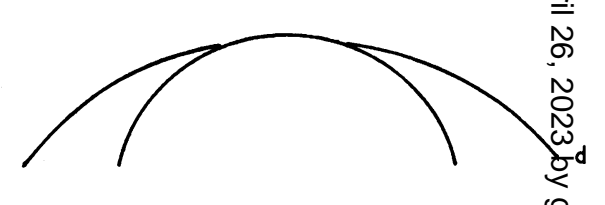

(D) EFFECT OF GHANGING THE POSITION OF THE BALL

Membrane profiles were plotted with an air flow of $200 \mathrm{ml} . / \mathrm{min}$. when the ball projected ${ }^{\text {f }}$ above the plane of the lid by $0 \cdot 6, \mathrm{I} \cdot 0, \mathrm{I} \cdot 5, \mathrm{I} \cdot 75,2 \cdot 0,2 \cdot 25$, and $2 \cdot 5 \mathrm{~cm}$.

The aperture in the membrane which was cut to a diameter of $1 \cdot 0 \mathrm{~cm}$. before stretching, increased by a small amount at each forward movement of the ball, showing that theo tension in the membrane was changed by this procedure (Figs $5 a, b, c, d$ ). 
Forward movement of the ball at constant air flow resulted in an increased forward bowing of the membrane. A selection of the resulting profiles is shown in Fig. 5. The pressure behind the membrane also increased as the ball was moved forward (Table IV).
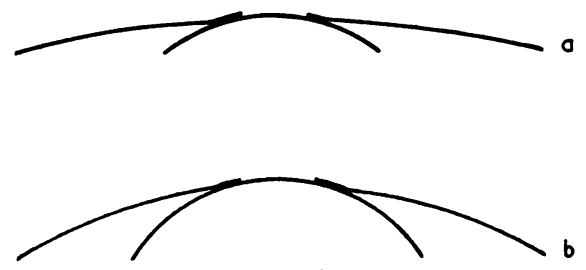

FIG. 5 Profiles of single-thickness membrane at an air flow of $200 \mathrm{ml}$./min., the ball being set to project

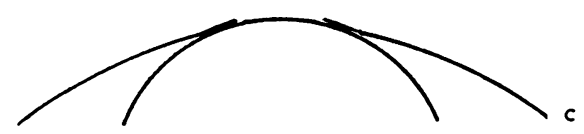
(a) $0.6 \mathrm{~cm}$., (b) I $5 \mathrm{~cm}$., (c) $2.0 \mathrm{~cm}$., (d) $2.5 \mathrm{~cm}$. above plane of lid

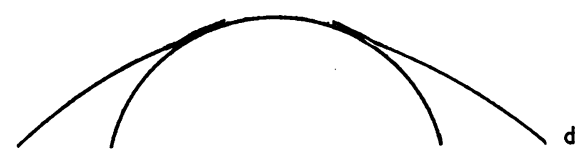

Table IV Results from fourth experiment to study effects of changing position of ball, with air flow $200 \mathrm{ml} . / \mathrm{min}$.

Ball projection above plane of lid $(\mathrm{cm}$.

Pressure behind membrane (cm. water)

Resistance to flow (cm. water/l./min.)

\begin{tabular}{lllllll}
0.6 & $1 \cdot 0$ & $1 \cdot 5$ & $1 \cdot 75$ & $2 \cdot 0$ & $2 \cdot 25$ & 2.5 \\
\hline $2 \cdot 0$ & 4.6 & 9.6 & $11 \cdot 0$ & $11 \cdot 9$ & $12 \cdot 5$ & $13 \cdot 0$ \\
\hline 10 & 23 & $4^{8}$ & 55 & 59 & 63 & 65
\end{tabular}

\section{Discussion}

\section{(A) THE ANALOGY}

Interpretation of the results of these experiments depends on an analogy between the iris and a stretched elastic annular membrane. This analogy may be supported in two ways:

(I) The analogy appears to be implicit in discussions of the pupil block mechanism, although it is not directly stated. The behaviour of a physiological system depending on mechanics for its interpretation should be imitable by a mechanical model.

(2) It is not likely that a muscle-controlled membrane would behave in a more than elastic manner, that is, that it would decrease in tonus as it was put under tension. The reverse is more likely, that it would become more rigid as its tension rose and in this case the succeeding arguments would still apply. 
(B) TIE PUPIL, BLOGK HYPOTHESIS

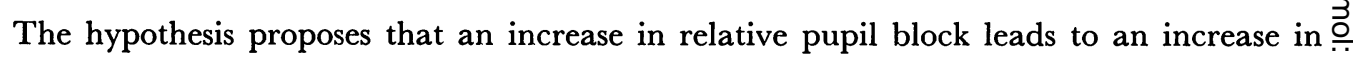
iris bombé. It is considered that the increased block may be brought about in one or $\vec{F}$ more of three ways; by an increase in tension in the iris; by a mid-dilated position of the pupil; or by a forward movement of the lens.

\section{(I) Changes in iris tension}

Several authors have suggested that an increase in iris tension, caused by the extreme meiosis of drugs or by co-contraction of the sphincter and dilator muscles, would lead to. an increased pupil block and hence an increase in iris bombé (Chandler, 1952; Becker and Shaffer, 1965; Lowe, 1967; Pollack, 1967; Mapstone, r968; Boyd, r968).

In the model, doubling of the membrane tension increased the resistance to air flow between the membrane and the ball-the equivalent of pupil block in the eye (compare $\stackrel{+}{\omega}$ Tables I and II). Despite this increase in resistance, the shape of the membrane was unchanged at comparable air flows, and the model gave no support to the hypothesis. The difference in the computed contact areas between the single and double membranes 5 is probably due to experimental error but, even if the difference is real, the hypothesis remains unsupported.

How is this to be explained? In discussion of the mechanism of acute glaucoma, it is $\stackrel{\supset}{5}$ usually assumed that the rate of aqueous secretion is constant. Two variables then remain $\vec{\theta}$ relating to flow through the pupil; the pressure differential between posterior and anterior. chambers; and the resistance to flow. If both the pressure differential and the resistance to flow depend on the tension in the iris, changes in iris tension should have a similar effect on both parameters.

In each of the first two series of experiments described here, as the air flow increased $\frac{Q}{\varnothing}$ and the membrane moved forward into the "bombé" position, its central aperture did not $\stackrel{2}{\vec{*}}$ increase in diameter. Since the aperture size gives an indication of the tension in the 3 membrane, it is apparent that the tension scarcely changed as the membrane moved forward, and changing tension could not explain the rising pressure in the space behind the membrane.

However, when the pressure behind the membrane was compared with the area of membrane not in contact with the ball-the "free" membrane exposed to the air in the posterior space-an approximately linear relationship was found, with the slope of the line for the doubled membrane steeper than that for the single membrane (Fig. 6).

Evidently two factors determine the pressure behind the membrane: the tension in the membrane (which did not change with changing flow but was doubled by doubling the membrane) and the area of membrane not in contact with the ball. At any given flow, $N$ doubling the membrane caused an increase in pressure without a change in contact area. $N$

Similarly the resistance to flow must depend on the pressure between the membrane and the ball, and on the area of contact between the two. The contact pressure was not? measured in these experiments, but it is likely that it too was dependent on the membranee tension. If this is so then an increased tension in the membrane could lead to an increased resistance to flow without a change of contact area.

Since the membrane curvature did not change when the membrane tension was $\hat{O}^{\circ}$ doubled, the pressure behind the membrane must have risen in proportion to the resistance to flow. 


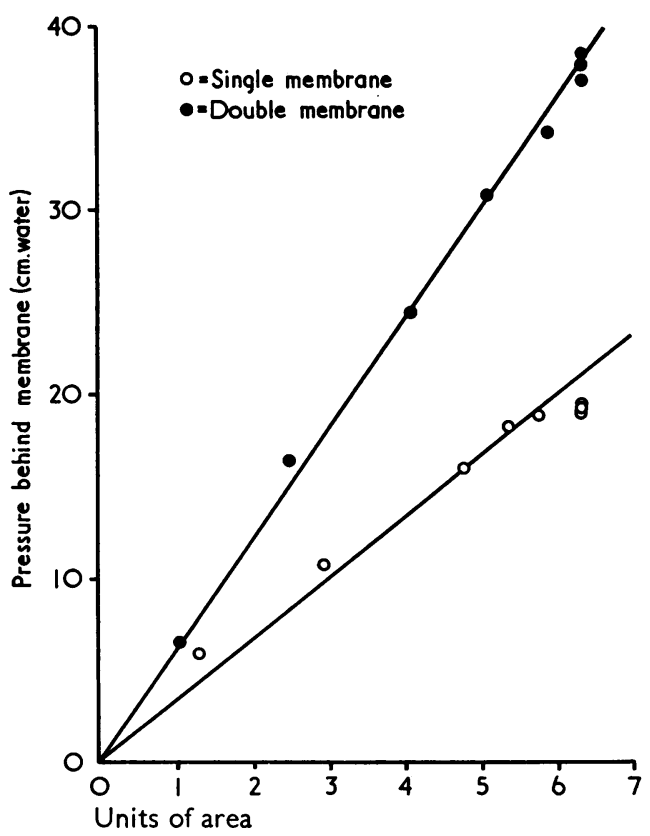

FIG. 6. Relationship between pressure behind membrane and area of membrane exposed to posterior space

\section{(2) Diameter of the pupil}

It is widely accepted that a position of mid-dilation of the pupil in a pre-disposed eye carries an especial risk of precipitating acute glaucoma, and this has been assumed to be because pupil block is still a significant factor while the periphery of the iris is now relatively lax (for example, see Chandler, I952; Becker and Shaffer, 1965).

There was no evidence in the behaviour of the model to support this theory. As the membrane aperture was increased the area of contact between the membrane and the ball decreased, the resistance to flow decreased, and the membrane bowed less.

In this experiment it was not possible to keep the tension constant while changing the aperture, because there was no direct method of regulating the tension. However, it has already been shown that, at a given flow, the membrane curvature was independent of its tension, so that this is not likely to lead to a significant error.

If a mid-dilated position of the pupil is indeed especially dangerous, it is probably for reasons other than its effect on pupil block, a possibility discussed in Section $\mathbf{C}$ below.

\section{(3) Forward movement of the lens}

Barkan (1954) proposed that a forward movement of the lens caused by accumulation of fluid in the posterior compartment of the eye might be the cause of increased pupil block leading to acute glaucoma. This view is supported by the studies of Christensen and Irvine (1966), Bleeker (1963), and Bleeker, van Haeringen, and Glasius (1963), but is opposed by those of Rosengren (1950).

Moving the ball forward in the model produced a progressive increase in resistance to air flow (Table IV) which was associated with a progressive increase in the forward bowing of the peripheral part of the membrane. Thus Barkan's hypothesis is supported 
by the behaviour of the model. Further studies of the changes in anterior chamber dept associated with acute glaucoma would be of value.

(c) OTHER ASPECTS OF THE BEHAVIOUR OF THE MODEL

The model has been shown to support only one of the three mechanisms proposed for the means by which increased pupil block may lead to acute glaucoma. It also suggest another factor which may be important in the genesis of the disease.

In the experiments described here, the ball was fixed to the centre rod so that the forces acting on the ball could not be assessed. However, it is probable that two opposing forces are involved. The stretched membrane tended to force the ball back into the jar. and this force was greatest when air flow was nil-a condition comparable to that of the eye after peripheral iridectomy. Increasing membrane aperture would decrease this force, and increased membrane tension would increase it.

There is also a force tending to displace the ball forwards, pushing it through the्टे membrane aperture. This phenomenon was studied by Koster (1895) who constructed a model to demonstrate how the lens acted as a valve in the pupil aperture. He showed that an unsuspended ball could be made to block the central aperture in an annula elastic membrane by applying a large pressure differential across the membrane. The ball would stay in that position as the pressure differential was reduced and would nof fall away from the aperture until the pressure differential was only that of a few $\mathrm{cm}$. of water. The same observation was made in a rather different form by Moses (1963).

In a stable state, any difference between these forces must be balanced by the suspensory system of the ball, in this case the threaded rod.

In the eye the iris corresponds to the elastic membrane, the pressure differential between posterior and anterior chambers to the pressure behind the membrane, and the zonulam tension to the screw thread on the ball. Accommodation, usually associated with meiosis would slacken the zonule. If the pupil dilated at the same time, those forces holding the lens back would be reduced, and forward displacement of the lens could occur. It is suggested that the balance between these forces may govern the position of the lens, and that a particular form of imbalance may lead to its forward displacement in acute glaucoma.

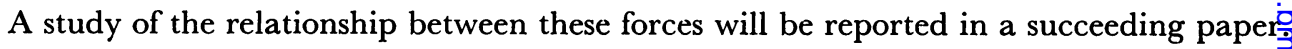

\section{Summary}

The pupil block hypothesis relating to the genesis of acute glaucoma was tested on a mode?

The apparatus was relatively simple, but the results were clearly defined. Only tho theory that forward movement of the lens might precipitate acute glaucoma could b supported. Implications for further studies are discussed.

Our thanks are due to Mr. Howells of Shandon-Elliott Ltd., Liverpool, who made the model, and to Mrw T. D. H. Gray for his helpful discussion and criticism.

\section{References}

barkan, o. (i954) Amer. J. Ophthal., 37, 332 BECKER, B., and SHAFFER, R. N. (I965) "Diagnosis and Therapy of the Glaucomas", 2nd ed., p. I5 ID Mosby, St. Louis 
BLeeker, G. M. (1963) Amer. J. Ophthal., 55, 964

--, VAN HAERINGEN, N. J., and GLASIUS, E. (1963) Ibid., 56, 56 I

воYп, в. F. (1968) "Highlights of Ophthalmology", vol. i I, No. 3. 1968 Series, Pan-American Institute of Ophthalmology.

Chandler, P. A. (1952) A.M.A. Arch. Ophthal., 47, 695

Christensen, L., and IRvine, A. R., JR. (1966) Arch. Ophthal. (Chicago), 75, 490

Koster, w. (1895) v. Graefes Arch. Ophthal., 41, abt 2, p. 98

LOWE, R. F. (1966) Brit. J. Ophthal., 50, 385

- (1967) Ibid., 5I, 727

MAPSTONE, R. (I968) Ibid., 52, I9

MOSES, R. A. (1963) In "Modern Ophthalmology", ed. A. Sorsby, vol. I, p. 296. Butterworths, London

POLLACK, I, P. (1967) In "Symposium on Glaucoma: Transactions of the New Orleans Academy of

Ophthalmology", p. 31. Mosby, St. Louis

rosengren, B. (1950) Arch. Ophthal. (Chicago), 44, 523 